\title{
Binuclear Schiff Base Complex of Manganese(III) as a Neutral Carrier for a Highly Selective Iodide Electrode
}

\author{
Qin ZhaO, ${ }^{* \dagger}$ Ruo YUan,** Yaqin ChaI,** Lan Xu,** Jiancun Chen,* and Zhongxiu Zhang* \\ *School of Chemistry and Chemical Engineering, Nantong University, Nantong 226007, China \\ **Chongqing Key Laboratory of Analytical Chemistry, School of Chemistry and Chemical Engineering, \\ Southwest University, Chongqing 400715, China
}

\begin{abstract}
A new highly selective iodide electrode incorporating a binuclear manganese(III) complex, bis(salicylaldehydeaminopropanol)dichloroaceticdimanganese(III) $\left[\mathrm{Mn}(\mathrm{III})_{2}\right.$-BSAPDCA], as a neutral carrier is described. The electrode displays an anti-Hofmeister selectivity sequence: iodide $\gg$ perchlorate $>$ salicylate $>$ thiocyanate $>$ nitrate $>$ bromide $>$ nitrite $>$ chloride $>$ sulfate. The excellent selectivity for iodide is related to a direct interaction between the central $\mathrm{Mn}$ (III) atom and iodide and a steric effect associated with the structure of the carrier, which is supported by UV spectroscopy and AC impedance techniques. The electrode exhibits a near-Nernstian potentiometric linear response range to iodide from $1.0 \times 10^{-1}$ to $2.0 \times 10^{-5} \mathrm{~mol} / \mathrm{L}$ with a detection limit of $8.0 \times 10^{-6} \mathrm{~mol} / \mathrm{L}$ and a slope of -60.3 $\mathrm{mV} /$ decade in $\mathrm{pH} 3.0$ of phosphate buffer solutions at $20^{\circ} \mathrm{C}$. From a comparison of the potentiometric response characteristics between a binuclear manganese(III) complex, $\mathrm{Mn}(\mathrm{III})_{2}$-BSAPDCA, and a mononuclear manganese(III) complex, Mn(III)-BSAPB, an enhanced response towards iodide from a binuclear metallic complex-based electrode was observed. The electrode, based on binuclear manganese(III) complex, was successfully applied to the determination of inorganic total iodine in iodized table salt with satisfactory results.
\end{abstract}

(Received December 8, 2006; Accepted June 4, 2007; Published November 10, 2007)

\section{Introduction}

Carrier-based ion-selective electrodes perform simple procedures, with a fast response, high selectivity and sensitivity, wide linear range and low cost, and can be widely applied to direct and rapid detection in chemical, clinical and environmental analyses. ${ }^{1}$

Traditional liquid-membrane electrodes for anions based on ion exchangers, such as lipophilic quaternary ammonium or phosphonium salts, always display the classical Hofmeister selectivity sequence: perchlorate $>$ thiocyanate $>$ iodide $\approx$ salicylate $>$ nitrate $>$ bromide $>$ nitrite $>$ chloride $>$ sulfate, in which the membrane selectivity is mainly dominated by the free energy of hydration of the ions involved., ${ }^{2,3}$ It is difficult to prepare useful electrodes for anions behind perchlorate in the Hofmeister selectivity sequence. Thus, research on antiHofmeister sensing materials with high selectivity for given anions is an expeditiously expanding domain in chemical sensors. Recently, electrodes using plasticized poly(vinyl chloride) (PVC) membranes incorporating derivatives of vitamin $\mathrm{B}_{12}$, organotin species, metalloporphyrins, metallophthalocyanines and other transitional metal complexes demonstrated potentiometric anion selectivity sequences that were remarkably different from the Hofmeister pattern; the mechanism of these deviations was involved in a specific interaction between the central metal and the analyte anion. ${ }^{4-12}$ Most of these electrodes exhibited priority of response to thiocyanate, salicylate and nitrite, respectively. ${ }^{4-12}$

The determination of iodide in food, medicine and

$\dagger$ To whom correspondence should be addressed. environment samples is very important, because iodine is an indispensable microelement to humans. Recent studies in our laboratory showed that solvent polymeric membrane electrodes incorporating some Schiff-base complexes of cobalt(II) as carriers exhibited high selectivity for iodide. ${ }^{13-16}$ However, Schiff-base complexes of cobalt(II) can reversibly coordinate oxygen, and as ionophores they will be influenced by oxygen in air. ${ }^{13-19}$ Because Schiff-base complexes of manganese(III) are more stable than Schiff-base complexes of cobalt(II), an electrode incorporating a Schiff-base complex of manganese(III) with a substantial improvement in good stability, long lifetime, oxygen independence and high selectivity towards iodide is of considerable interest.

On the other hand, many of the electrodes were based on mononuclear metallic complexes as carriers. ${ }^{4-16}$ An enhanced response towards the analyte anion from a binuclear metallic complex-based electrode was observed, showing that binuclear metallic complexes may become a new promising class of carriers for anion electrodes. ${ }^{20-22}$

In this paper, a binuclear Schiff-base complex of manganese(III) bis(salicylaldehydeaminopropanol)dichloroaceticdimanganese(III) [Mn(III) $)_{2}$-BSAPDCA] (Fig. 1(a)) synthesized in our laboratory was incorporated into a plasticized PVC membrane with 2-nitrophenyl octyl ether (o-NPOE) as a plasticizer to prepare a highly selective iodide electrode. A comparison of the potentiometric response characteristics between the binuclear and mononuclear manganese(III) complexes was made, exhibiting that the electrode based on a binuclear manganese(III) complex, $\mathrm{Mn}(\mathrm{III})_{2}$-BSAPDCA, demonstrated a highly selective response to iodide with a wider linear range and lower detection limit. 


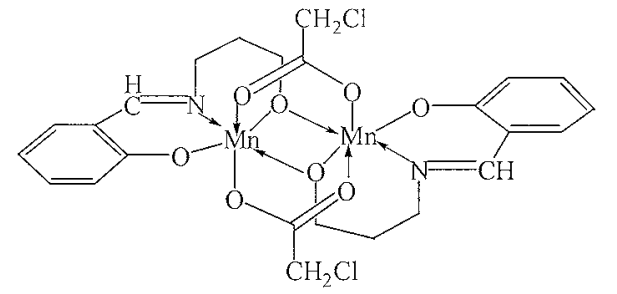

(a)

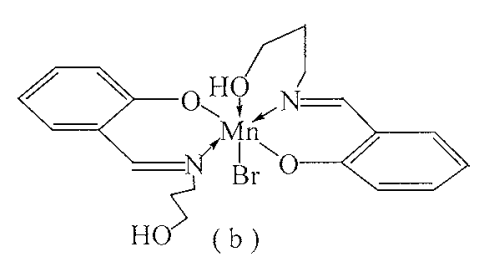

Fig. 1 Structures of $\mathrm{Mn}(\mathrm{III})_{2}$-BSAPDCA (a) and Mn(III)-BSAPB (b).

\section{Experimental}

\section{Apparatus}

All potentiometric and $\mathrm{pH}$ measurements were made with a pH meter (MP 230, Mettler-Toledo, Switzerland) and a digital ion analyzer (Model PHS-3C, Dazhong Instruments, Shanghai, China). The cells used for $\mathrm{mV}$ measurements were of the following type: $\mathrm{Hg}, \mathrm{Hg}_{2} \mathrm{Cl}_{2} ; \mathrm{KCl}$ (satd.), sample solution; membrane, $0.1 \mathrm{~mol} / \mathrm{L} \mathrm{KCl} ; \mathrm{AgCl}, \mathrm{Ag}$. Organometallic complexes synthesized were characterized by elemental analysis with a C-H-N-O-S-Rapid Elemental Analyzer (D-6450, Heracus, Germany). UV absorption spectra were obtained on a UV/VIS spectrophotometer (Lambda 17, Perkin-Elmer, USA). The AC impedance of the electrode membrane was recorded with an impedance-measurement unit (IM6e, ZAHNER Elektrik, Germany) equipped with THALES software 6.88

\section{Reagents and chemicals}

Bis(salicylaldehydeaminopropanol)dichloroaceticdimanganese(III) $\left[\mathrm{Mn}(\mathrm{III})_{2}\right.$-BSAPDCA $]$ and bis(salicylaldehydeaminopropanol)bromomanganese(III) [Mn(III)BSAPB] (Fig. 1(b)) were prepared as described in a reference. ${ }^{23}$ A plasticizer, 2-nitrophenyl octyl ether (o-NPOE), was synthesized as described by Horning. ${ }^{24}$ Poly(vinyl chloride) (PVC) powder of chromatographic grade was supplied by Shanghai Chemical Co. (Shanghai, China). All other chemicals used were of analytical-reagent grade, and water used throughout was purified by a double distillation and deionization system. The solutions were buffered with 0.01 $\mathrm{mol} / \mathrm{L} \mathrm{H}_{3} \mathrm{PO}_{4}$ and adjusted to $\mathrm{pH} 3.0$ with a concentrated $\mathrm{NaOH}$ solution.

\section{Sensor construction}

The membrane composition was optimized by using an orthogonal experimental design with the electrode linear response range for iodide as the object function for optimization. The optimum composition found was $2.5 \%(\mathrm{w} / \mathrm{w})$ in ionophore, $31 \%(\mathrm{w} / \mathrm{w})$ in PVC and $66.5 \%(\mathrm{w} / \mathrm{w})$ in $o-\mathrm{NPOE}$ The PVC membrane electrodes were fabricated from various carriers and assembled according to Thomas and his coworkers. ${ }^{25,26}$

\section{UV absorption spectra}

The UV absorption spectra of the $\mathrm{Mn}(\mathrm{III})_{2}$-BSAPDCA

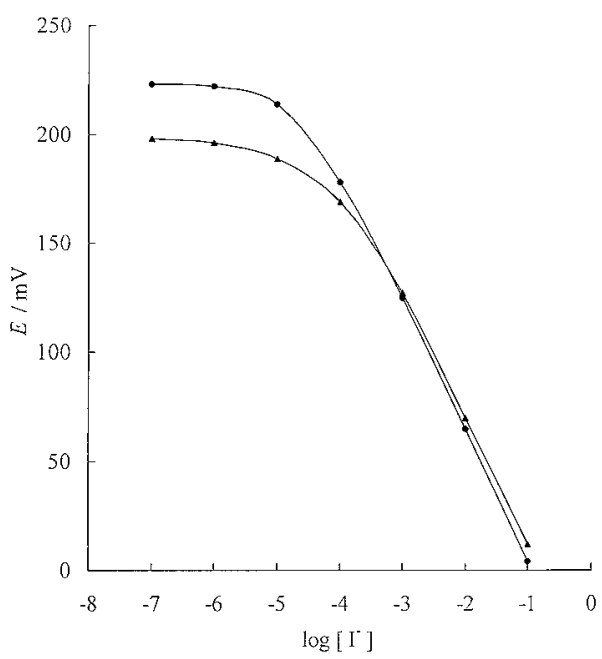

Fig. 2 Potentiometric response curves of electrodes doped with $\mathrm{Mn}(\mathrm{III})_{2}$-BSAPDCA $(\bullet)$ and $\mathrm{Mn}(\mathrm{III})-\mathrm{BSAPB}(\boldsymbol{\Delta})$ in $0.01 \mathrm{~mol} / \mathrm{L}$ phosphate-buffered solutions, $\mathrm{pH}$ 3.0.

chloroform solutions were recorded after shaking them with aqueous $0.1 \mathrm{~mol} / \mathrm{L} \mathrm{KI}(\mathrm{pH} \mathrm{3.0)}$ ) and a blank buffer solution for $30 \mathrm{~min}$, respectively.

\section{AC impedance}

The AC impedance of the electrode membrane containing $\mathrm{Mn}(\mathrm{III})_{2}$-BSAPDCA was recorded. The working electrode was a $\mathrm{Ag} / \mathrm{AgCl}$ foil with a $0.5-\mathrm{cm}^{2}$ area. A saturated calomel electrode (SCE) and a Pt foil with $0.5-\mathrm{cm}^{2}$ area were used as a reference electrode and a counter electrode, respectively. The frequency region used was $10^{-2}-10^{6} \mathrm{~Hz}$ and the $\mathrm{AC}$ amplitude was $50 \mathrm{mV}\left(20^{\circ} \mathrm{C}\right)$.

\section{Results and Discussion}

\section{Potentiometric response characteristics of electrodes}

The potentiometric response characteristics of electrodes containing different carriers toward iodide are shown in Fig. 2. An electrode incorporating a binuclear manganese(III) complex, $\mathrm{Mn}(\mathrm{III})_{2}$-BSAPDCA, exhibited a near-Nernstian potentiometric linear response range to iodide from $1.0 \times 10^{-1}$ to $2.0 \times 10^{-5}$ $\mathrm{mol} / \mathrm{L}$ with a detection limit of $8.0 \times 10^{-6} \mathrm{~mol} / \mathrm{L}$ and a slope of $-60.3 \mathrm{mV} /$ decade in $\mathrm{pH} 3.0$ of phosphate buffer solutions at $20^{\circ} \mathrm{C}$. The time required for the electrode to reach $95 \%$ response was less than $30 \mathrm{~s}$. The DC resistance of the electrode membrane was $940 \mathrm{k} \Omega(n=6)$. The standard deviation of the electrode potential readings over a period of $10 \mathrm{~h}$ in $0.01 \mathrm{~mol} / \mathrm{L}$ phosphate-buffered solution $(\mathrm{pH} 3.0)$ containing $1.0 \times 10^{-3}$ $\mathrm{mol} / \mathrm{L} \mathrm{KI}$ was $0.51 \mathrm{mV}(n=36)$, and the potential readings for the electrode dipped alternately into stirred solutions of $1.0 \times$ $10^{-3}$ and $1.0 \times 10^{-4} \mathrm{~mol} / \mathrm{L} \mathrm{KI}$ showed a standard deviation of $0.74 \mathrm{mV}$ over $2 \mathrm{~h}(n=6)$. The electrode could be used continuously for more than 2 months, and did not show any detectable loss of its performance characteristics. The potentiometric response characteristics of an electrode incorporating a mononuclear manganese(III) complex, $\mathrm{Mn}$ (III)BSAPB, are rather poor (Fig. 2). An electrode incorporating $\mathrm{Mn}(\mathrm{III})-\mathrm{BSAPB}$ showed a relatively narrow response linear range, high detection limit, and low response slope. 


\section{pH effect on the electrode response}

Figure 3 illustrates the influence of the $\mathrm{pH}$ on the potentiometric response characteristics of an electrode doped with $\mathrm{Mn}(\mathrm{III})_{2}$-BSAPDCA toward iodide. The linear-response range and the slope deteriorating with increasing solution $\mathrm{pH}$ can be explained by coordination competition between $\mathrm{I}^{-}$and $\mathrm{OH}^{-}$, and increasing competition of $\mathrm{OH}^{-}$at higher $\mathrm{pH}$ values. A similar effect of the $\mathrm{pH}$ on the potentiometric response for electrodes based on porphyrin and vitamin $\mathrm{B}_{12}$ derivatives was observed previously. 27,28

\section{Selectivity}

The potentiometric selectivity coefficients, $\log K_{\mathrm{I}_{\mathrm{j}, \mathrm{j}^{-}}}^{\mathrm{pot}}$ of the electrodes containing $\mathrm{Mn}(\mathrm{III})_{2}$-BSAPDCA and $\mathrm{Mn}$ (III)-BSAPB were determined by a separate solution method and compared with that of an electrode containing a quaternary ammonium salt, hexadecyltrioctylammonium iodide (HTOAI) ${ }^{13}$ (Table 1). The electrode containing $\mathrm{Mn}(\mathrm{III})_{2}$-BSAPDCA exhibited excellent selectivity to iodide, and displayed an anti-Hofmeister selectivity sequence: iodide $\gg$ perchlorate $>$ salicylate $>$ thiocyanate $>$ nitrate $>$ bromide $>$ nitrite $>$ chloride $>$ sulfate An electrode incorporating a mononuclear manganese(III)

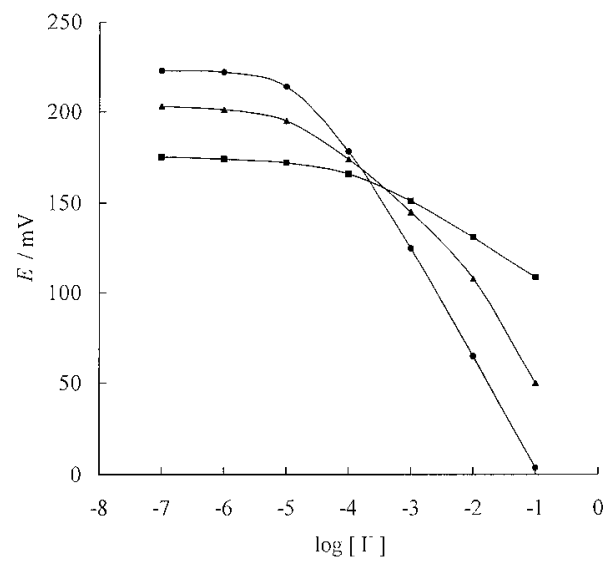

Fig. 3 Potentiometric response curves of an electrode doped with $\mathrm{Mn}(\mathrm{III})_{2}$-BSAPDCA at different $\mathrm{pH}$ values of $0.01 \mathrm{~mol} / \mathrm{L}$ phosphatebuffered solutions: $(\bullet) \mathrm{pH} 3.0,(\boldsymbol{\Delta}) \mathrm{pH} 4.0$ and (口) $\mathrm{pH}$ 6.0. complex, Mn(III)-BSAPB, showed poor selectivity to iodide.

\section{Mechanism to iodide response}

That PVC membrane electrodes incorporating some organometallic compounds as carriers exhibited an antiHofmeister selective behavior was mainly based on the geometric configuration of the carrier and a specific interaction between the central metal in an organometallic compound and the analyte anion, rather than the lipophilicity of the anion or a simple electrostatic interaction with the anion. ${ }^{28}$ An electrode doped with $\mathrm{Mn}(\mathrm{III})_{2}$-BSAPDCA exhibited excellent potentiometric selectivity for iodide, which is mainly related to a direct interaction between the central $\mathrm{Mn}$ (III) atom and iodide and a steric effect associated with the structure of the carrier. In the complex $\mathrm{Mn}(\mathrm{III})_{2}$-BSAPDCA, the $\mathrm{Mn}(\mathrm{III})$ atom is sixcoordinated and the coordination sphere can be described as a distorted octahedron, due to the Jahn-Teller effect. ${ }^{23}$ The elongated $\mathrm{Mn}-\mathrm{O}$ bonds in the axial direction are longer and weaker than the $\mathrm{Mn}-\mathrm{O}$ and $\mathrm{Mn}-\mathrm{N}$ bonds in the equatorial plane. On the other hand, the chelation strength of the carbonyl group is relatively weak in solution, and the coordinate carbonyl group in $\mathrm{Mn}(\mathrm{III})_{2}$-BSAPDCA may be replaced by $\mathrm{I}^{-}$in the solution reversely. This agrees with the results obtained by Gopinathan ${ }^{29}$ and $\mathrm{Li}^{30}$ Therefore, the response mechanism of an electrode doped with $\mathrm{Mn}(\mathrm{III})_{2}$-BSAPDCA is suggested to involve the central $\mathrm{Mn}$ (III) atom serving as a coordinate site for iodide, and the coordinate replacement may take place in the axial direction (Fig. 4). Compared with the mononuclear manganese(III) complex, Mn(III)-BSAPB, the response towards iodide from a binuclear manganese(III) complex, $\mathrm{Mn}(\mathrm{III})_{2}$-BSAPDCA, based electrode is enhanced, which can be explained as follows: on the one hand, the binuclear complex possesses a higher lipophilicity $(\log P=2.74)$ than mononuclear complex $(\log P=$ 2.01 ), which is favorable to increase the solubility of the carrier in the membrane; on the other hand, because $\mathrm{Mn}(\mathrm{III})_{2-}$ BSAPDCA has two central metals, the chance of an interaction towards iodide from the central metal $\mathrm{Mn}$ (III) is improved. The coordination numbers and association constants of the axial coordination reaction of complexes $\mathrm{Mn}(\mathrm{III})_{2}$-BSAPDCA and $\mathrm{Mn}$ (III)-BSAPB towards iodide were measured by means of a spectra technique. ${ }^{31}$ The coordination numbers for $\mathrm{Mn}(\mathrm{III})_{2^{-}}$ BSAPDCA and Mn(III)-BSAPB were all 1. The association constant $\ln K^{\theta}$ of iodide to $\mathrm{Mn}(\mathrm{III})_{2}$-BSAPDCA was 12.75 , and

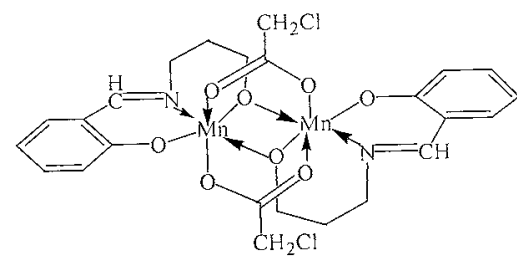

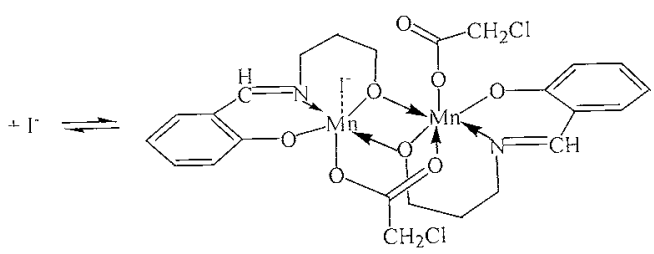

Fig. 4 Suggested coordination scheme of $\mathrm{Mn}(\mathrm{III})_{2}$-BSAPDCA with iodide.

Table 1 Selectivity coefficients, $\log K_{\Gamma^{-j^{n}}}^{\text {pot }}$, for electrodes incorporating Mn(III $)_{2}$-BSAPDCA, Mn(III)-BSAPB and HTOAI, respectively

\begin{tabular}{|c|c|c|c|c|c|c|c|c|c|}
\hline \multirow{2}{*}{ Carrier } & \multicolumn{9}{|c|}{ Interfering ion } \\
\hline & $\mathrm{I}^{-}$ & $\mathrm{ClO}_{4}^{-}$ & $\mathrm{Sal}^{-}$ & $\mathrm{SCN}^{-}$ & $\mathrm{NO}_{3}^{-}$ & $\mathrm{Br}^{-}$ & $\mathrm{NO}_{2}^{-}$ & $\mathrm{Cl}^{-}$ & $\mathrm{SO}_{4}^{2-}$ \\
\hline $\mathrm{Mn}(\mathrm{III})_{2}$-BSAPDCA & 0 & -1.9 & -2.1 & -2.2 & -3.5 & -3.7 & -3.8 & -4.1 & -4.6 \\
\hline Mn(III)-BSAPB & 0 & -1.5 & -1.1 & -2.5 & -3.2 & -3.4 & -3.0 & -3.3 & -4.3 \\
\hline HTOAI & 0 & 1.9 & 0 & 0.5 & -1.4 & -2.0 & -2.8 & -3.1 & -4.2 \\
\hline
\end{tabular}

a. Selectivity coefficients obtained in $0.01 \mathrm{~mol} / \mathrm{L}$ phosphate-buffered solutions ( $\mathrm{pH} 3.0$ ). 


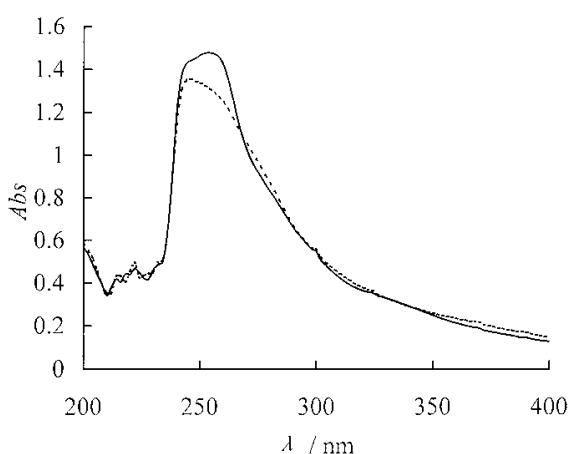

Fig. 5 UV absorption spectra of chloroform solutions of $\mathrm{Mn}(\mathrm{IIII})_{2}-$ BSAPDCA (--.--) and $\mathrm{Mn}(\mathrm{IIII})_{2}$-BSAPDCA treated with $0.1 \mathrm{~mol} / \mathrm{L}$ $\mathrm{KI}(-$ ).

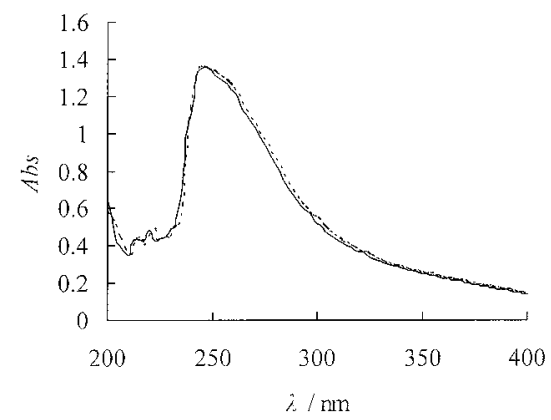

Fig. 6 UV absorption spectra of chloroform solutions of $\mathrm{Mn}(\mathrm{III})_{2^{-}}$ BSAPDCA (-.--) and $\mathrm{Mn}(\mathrm{III})_{2}$-BSAPDCA treated with $0.1 \mathrm{~mol} / \mathrm{L}$ $\mathrm{KClO}_{4}(-)$.

that to $\mathrm{Mn}$ (III)-BSAPB was 9.23. The experimental result that the association constant of iodide to $\mathrm{Mn}(\mathrm{III})_{2}$-BSAPDCA was higher than that of $\mathrm{Mn}(\mathrm{III})-\mathrm{BSAPB}$ confirmed the enhanced selectivity of $\mathrm{Mn}(\mathrm{III})_{2}$-BSAPDCA. Binuclear metallic complexes are promising as a new class of carrier for anion electrodes. ${ }^{20-22}$

In order to investigate the mechanism to the iodide response, UV absorption spectra and AC impedance were obtained. The $\mathrm{UV}$ absorption spectra of $\mathrm{Mn}(\mathrm{III})_{2}$-BSAPDCA in $\mathrm{CHCl}_{3}$ (Fig. 5) confirm the interaction between the carrier and iodide. The peak showing a considerable red shift of about $12 \mathrm{~nm}$ and a substantial increase in absorbance between shaking the $\mathrm{Mn}(\mathrm{III})_{2}$-BSAPDCA chloroform solutions with aqueous 0.1 $\mathrm{mol} / \mathrm{L} \mathrm{KI}(\mathrm{pH} \mathrm{3.0)}$ and a blank buffer solution for $30 \mathrm{~min}$, respectively, suggests that the coordination between the carrier and iodide has taken place. At the same time, the effect of $\mathrm{ClO}_{4^{-}}(0.1 \mathrm{~mol} / \mathrm{L})$ on the UV absorption spectra of a $\mathrm{Mn}(\mathrm{III})_{2^{-}}$ BSAPDCA chloroform solution was also investigated, and no detectable change in the corresponding UV absorption spectra was observed (Fig. 6); similar spectra were also obtained when

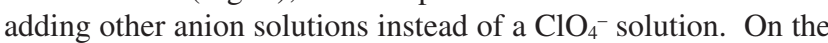
other hand, the iodide concentration decreased after the solvent extraction of iodide into a $\mathrm{Mn}(\mathrm{III})_{2}$-BSAPDCA chloroform solution, and the percentage of extraction was $62.07 \%$. The other anion concentration had almost no detectable decrease. All of these observations seem to support the hypothesis that the excellent potentiometric selectivity for iodide of the electrode is correlated with the unique coordination of iodide to the $\mathrm{Mn}(\mathrm{III})_{2}$-BSAPDCA.

Figure 7 illustrates the $\mathrm{AC}$ impedance of an electrode membrane incorporating $\mathrm{Mn}(\mathrm{III})_{2}$-BSAPDCA conditioned in

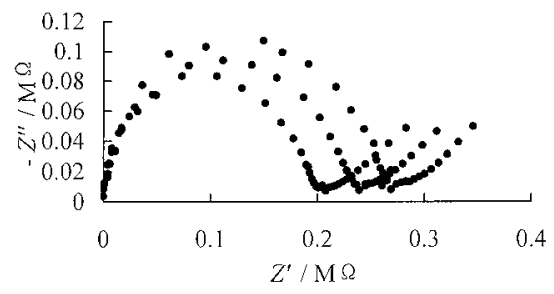

Fig. 7 Impedance plots of a PVC membrane containing $\mathrm{Mn}(\mathrm{III})_{2-}$ BSAPDCA (frequency, $10^{-2}-10^{6} \mathrm{~Hz}$; AC amplitude, $50 \mathrm{mV}$; temperature, $\left.20^{\circ} \mathrm{C}\right)$.

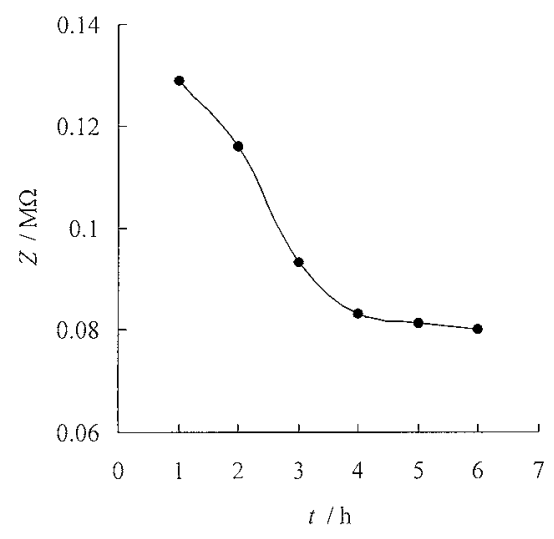

Fig. 8 Bulk resistance of an electrode membrane containing $\mathrm{Mn}(\mathrm{III})_{2}$-BSAPDCA conditioned in $1.0 \times 10^{-2} \mathrm{~mol} / \mathrm{L} \mathrm{KI}(\mathrm{pH} 3.0)$ with different times.

pH 3.0 phosphate buffer solution containing different concentration of $\mathrm{KI}$ for $4 \mathrm{~h}$. Perfect semicircle bulk impedance at high frequencies and Warburg impedance at low frequencies were observed. The bulk resistance of an electrode membrane containing $\mathrm{Mn}(\mathrm{III})_{2}$-BSAPDCA conditioned in $1.0 \times 10^{-2} \mathrm{~mol} / \mathrm{L}$ $\mathrm{KI}$ ( $\mathrm{pH}$ 3.0) with different times is shown in Fig. 8. The bulk resistance decreased with an increase in time. When the time was more than $4 \mathrm{~h}$, the decrease became very slow and the bulk resistance approached a plateau; $4 \mathrm{~h}$ was chosen as an appropriate time to be used for conditioning the electrode membrane in the AC impedance experiment. As can be seen in Fig. 7, when the concentration of KI was $1.0 \times 10^{-4}, 1.0 \times 10^{-3}$, and $1.0 \times 10^{-2} \mathrm{~mol} / \mathrm{L}$, respectively, the corresponding bulk impedance of the membrane was $0.107,0.094$, and $0.083 \mathrm{M} \Omega$. The bulk resistance of the membrane incorporating $\mathrm{Mn}(\mathrm{III})_{2}$ BSAPDCA decreased with increasing KI concentration, whereas that of carrier-free membrane remained almost constant. This phenomenon was related to the transfer of $\mathrm{I}^{-}$ across the solvent membrane, resulting from the interaction between $\mathrm{I}^{-}$and $\mathrm{Mn}(\mathrm{III})_{2}$-BSAPDCA. The Warburg impedance at low frequencies indicated that the transfer process of $\mathrm{I}^{-}$across the solvent membrane was diffusion-controlled. ${ }^{32,33}$

\section{Preliminary application}

An electrode incorporating $\mathrm{Mn}(\mathrm{III})_{2}$-BSAPDCA was successfully applied to the determination of inorganic total iodine in iodized table salt. Iodate in the salt sample was reduced by arsenious acid(III) in an acidic medium to produce iodide, and was analyzed by a calibration-curve method with a $\mathrm{Mn}(\mathrm{III})_{2}$-BSAPDCA based electrode. The inorganic total iodine obtained was $32.95 \times 10^{-4}(\mathrm{w} / \mathrm{w})(n=5)$, which was in fair 
agreement with the result given by the titration method $(33.27 \times$ $\left.10^{-4}(\mathrm{w} / \mathrm{w})(n=5)\right) \cdot^{34}$

\section{Conclusion}

In this paper, we have described a new highly selective iodide electrode incorporating a binuclear manganese(III) complex, bis(salicylaldehydeaminopropanol)dichloroaceticdimanganese(III) ( $\mathrm{Mn}(\mathrm{III})_{2}$-BSAPDCA), as a neutral carrier. This electrode exhibits a variety of good performance characteristics, including easy preparation and procedures, high selectivity and sensitivity, good stability and reproducibility, fast response and low cost. The electrode can be applied to the determination of iodide in actual samples.

\section{Acknowledgements}

Support of this study by the National Natural Science Foundation of China (29705001) and the Natural Science Foundation of Nantong University (05Z025) is gratefully acknowledged.

\section{References}

1. P. Bühlmann, E. Pretsch, and E. Bakker, Chem. Rev., 1998, 98, 1593.

2. W. E. Morf, "The Principles of Ion-Selective Electrodes and of Membrane Transport", 1981, Elsevier, New York.

3. K. Sollner and G. M. Shean, J. Am. Chem. Soc., 1964, 86, 1901.

4. U. Wuthier, H. V. Pham, R. Zund, D. Welti, R. J. J. Funck, A. Bezegh, D. Ammann, E. Prestsch, and W. Simon, Anal. Chem., 1984, 56, 535.

5. P. Schulthess, D. Ammann, W. Simon, C. Caderas, R. Stepanek, and B. Kraeutler, Helv. Chim. Acta, 1984, 67, 1026.

6. P. Schulthess, D. Ammann, B. Kraeutler, C. Caderas, R. Stepanek, and W. Simon, Anal. Chem., 1985, 57, 1397.

7. R. Stepanek, B. Krautler, P. Schulthess, B. Lindemann, D. Ammann, and W. Simon, Anal. Chim. Acta, 1986, 182, 83.

8. N. A. Chaniotakis, S. B. Park, and M. E. Meyerhoff, Anal. Chem., 1989, 61, 566

9. J. Z. Li, X. C. Wu, R. Yuan, H. G. Lin, and R. Q. Yu, Analyst, 1994, 119, 1363.

10. I. H. A. Badr, M. E. Meyerhoff, and S. S. M. Hassan, Anal. Chem., 1995, 67, 2613.

11. D. Liu, W. C. Chen, G. L. Shen, and R. Q. Yu, Analyst, 1996, 121,1495

12. N. N. Leyzerovich, N. V. Shvedene, Y. N. Blikova, L. G
Tomilova, and I. V. Pletnev, Electroanalysis, 2001, 13, 246.

13. R. Yuan, Y. Q. Chai, D. Liu, D. Gao, J. Z. Li, and R. Q. Yu, Anal. Chem., 1993, 65, 2572.

14. R. Yuan, Y. Q. Chai, D. Liu, and R. Q. Yu, Chin. Sci. Bull., 1994, 39, 573.

15. R. Yuan, Y. Q. Song, Y. Q. Chai, S. X. Xia, Q. Y. Zhong, B. Yi, M. Ying, G. L. Shen, and R. Q. Yu, Talanta, 1999, $48,649$.

16. J. Y. Dai, Y. Q. Chai, R. Yuan, X. Zhong, Y. Liu, and D. P. Tang, Anal. Sci., 2004, 20, 1661.

17. C. Floriani, M. Puppis, and F. Calderazzo, J. Organomet. Chem., 1968, 12, 209.

18. L. G. Marzilli, P. A. Marzilli, and J. Halpern, J. Am. Chem. Soc., 1971, 93, 1374.

19. J. H. Burness, J. G. Dillard, and L. T. Taylor, Synth. React. Inorg. Met.-Org. Chem., 1976, 6, 165.

20. D. Gao, D. Liu, R. Q. Yu, and G. D. Zheng, Fresenius J. Anal. Chem., 1995, 351, 484.

21. D. Liu, W. C. Chen, D. L. He, G. L. Shen, and R. Q. Yu, Chem. J. Chin. Univ., 1996, 17, 1528.

22. R. Yuan, X. L. Wang, L. Xu, Y. Q. Chai, Z. Y. Sun, X. Q. Huang, Q. F. Li, Q. Zhao, and L. Zhou, Electrochem. Commun., 2003, 5, 717.

23. C. G. Zhang, Y. J. Leng, J. M. Gu, D. J. Xu, and Y. Z. Xu, Chin. J. Inorg. Chem., 1999, 15, 583.

24. E. C. Horning, "Organic Syntheses, Collective Vol. III", 1955, Wiley, New York, 140.

25. G. J. Moody, R. B. Oke, and J. D. R. Thomas, Analyst, 1970, 95, 910 .

26. A. Craggs, G. J. Moody, and J. D. R. Thomas, J. Chem. Educ., 1974, 51, 541.

27. S. A. O'Reilly, S. Daunert, and L. G. Bachas, Anal. Chem., 1991, 63, 1278.

28. N. A. Chaniotakis, S. B. Park, and M. E. Meyerhoff, Anal. Chem., 1989, 61, 566.

29. S. Gopinathan, C. Gopinathan, and J. Gupta, Indian J. Chem., 1974, 12, 626.

30. Z. Q. Li, R. Yuan, M. Ying, Y. Q. Song, G. L. Shen, and R. Q. Yu, Talanta, 1998, 46, 943.

31. B. X. Zhu, W. J. Ruan, F. Gao, X. H. Cao, and Z. A. Zhu, Chem. J. Chin. Univ., 2005, 26, 412.

32. C. N. Cao and J. Q. Zhang, "An Introduction to Electrochemical Impedance Spectroscopy", 2002, Science Press, Beijing, 4.

33. M. Ying, R. Yuan, X. M. Zhang, Y. Q. Song, Z. Q. Li, G. L. Shen, and R. Q. Yu, Analyst, 1997, 122, 1143.

34. Chinese Standard Press Editorial Department, "Compilation of Chinese Standard, GB/T13025.7-1999, General Test Method in Salt Industry-Determination of Iodide Ion", 2000, Chinese Standard Press, Beijing, 229. 